\title{
Comer em tempos de Covid-19: a experiência de um morador em uma comunidade carente
}

Comer en tiempos de Covid-19: la experiencia de un residente en una comunidad pobre

Eating in times of Covid-19: a resident's experience in a needy community

Elaine Zanazi de Almeida ${ }^{1}$, Maria do Carmo Soares de Freitas², Gardênia Abreu Vieira Fontes ${ }^{3}$, Geilson Reis de Andrade ${ }^{4}$, Zilda Maria Dourado Silva ${ }^{5}$, Adriano de

Souza Santos ${ }^{6}$

\section{Contextualizando}

Esse trabalho trata de uma experiência de análise narrativa de um morador de uma comunidade carente, na cidade de Salvador, Bahia, Brasil, sobre o comer em tempos de isolamento social, frente à pandemia por Covid-19. Ante ao distanciamento físico necessário ao período, à coleta das narrativas ocorreu em dois encontros virtuais durante a primeira quinzena do mês de maio do ano 2020, através da metodologia de Entrevista Narrativa (EN).(1) As análises dessas narrativas ocorreram a partir de aproximações com os escritos de Gadamer.(2) A arte do processo interpretativo das experiências narradas sob a luz desse autor esculpiu repertórios de significados úteis às analogias factuais dos contextos territorial e pandêmico.

Escolhemos trabalhar com este método, para que os relatos narrados pelo morador estivessem respaldados, nas experiências e perspectivas simultâneas à pandemia, além de se tratar de uma sistematização importante deste período

\footnotetext{
1 Secretaria de Educação do Estado da Bahia. Conselho de Alimentação Escolar do Estado da Bahia (CAE-BAHIA), Bahia, Brasil. E-mail: elainesalmed@gmail.com

2 Escola de Nutrição e Faculdade de Medicina. Universidade Federal da Bahia. Bahia, Brasil. E-mail: carmofreitas@uol.com.br

${ }^{3}$ Centro Colaborador em Alimentação e Nutrição do Escolar - CECANE. Universidade Federal da Bahia, Brasil. E-mail: fontesgav@gmail.com

${ }^{4}$ Universidade do Estado da Bahia/UnEB. Bahia, Brasil. E-mail: geilsonreis2015@gmail.com

5 Universidade do Estado da Bahia. Bahia, Brasil E-mail: zildadourado@gmail.com

${ }^{6}$ Movimento Nacional de Catadores, da Federação de Pesca Artesanal da Bahia (FAPESCA) e da Coordenação Estadual de Comunidades Quilombolas (CONAQ). Bahia, Brasil. E-mail: souzaa.aadriano@gmail.com
} 
excecional em Saúde Pública, que pode ser relatado com riqueza de detalhes pelo autor narrativo originário daquele contexto socioterritorial específico.

No primeiro encontro virtual, apresentamos a proposta deste estudo ao autor das narrativas, um informante do sexo masculino, 40 anos de idade, nível de escolaridade superior, nascido na comunidade, habitante daquele território e integrante do Quilombo do Orobu ${ }^{7}$, com assinatura do Termo de Consentimento Livre e Esclarecido (TCLE). Elegeu-se esse morador devido ao seu reconhecido protagonismo, inclusive no período de pandemia. Por razões éticas, sua identidade nos relatos desta investigação encontra-se sob o pseudônimo Diogo.

No segundo encontro virtual, utilizando linguagem própria, espontânea e autogeradora, o informante narrou acontecimentos sobre 0 comer na sua comunidade e, fatos relacionados ao distanciamento social e alimentação, no contexto daquele território durante a pandemia, reconstruindo de forma coloquial os acontecimentos sociais a partir de sua perspectiva. As informações foram narradas em áudio e compartilhadas virtualmente com os autores deste estudo, para posterior transcrição e análise. (1)

\section{Simbolismos da Fome}

Comunidades carentes ou bairros populares na cidade de Salvador, Bahia, são povoadas majoritariamente por populações afrodescendentes. Dessa forma, há que se levar em conta, que as palavras compartilhadas pelo autor narrativo nesse estudo, descreveram suas experiências ancestrais remanescentes, quilombolas urbanos, num momento de enfrentamento de um fenômeno de saúde pública inédito neste século. A doença provocada pelo novo coronavírus no século XXI respondeu a um quando aconteceria uma nova pandemia infecciosa, questão levantada pela comunidade científica. ${ }^{(3)}$

No entanto, olhando para mais além desse horizonte, a Covid-19 fez entender que a atual alteração dos paradigmas da saúde desafiou problemas estruturais também nos âmbitos socioeconômicos e de Segurança Alimentar e Nutricional

7 Orobu: Léxico Banto. Quilombo formado no ano 1826, nas Matas do Urubu, no Sítio Cajazeira. Moura C. Rebeliões da Senzala: a questão social no Brasil. 3. ed. São Paulo: Lech Livraria Editora Ciências Humanas, 1981. 
(SAN), que vem sendo mantidos cronicamente pela sociedade brasileira nas comunidades vulneráveis. Algumas possibilidades de interpretação hermenêutica puderam ser vistas nesse aspecto da relação entre a ciência e a comunidade.

\begin{abstract}
As informações que chegam aqui são os meios de comunicação de massa e as fake news. A Ciência não chega aqui, não. Se a Ciência falar, para a gente é nada. Mas, se a TV falar, aí é outra coisa, entende? Entendemos que a comunidade está por sua conta. Então, tomamos nossas providências, baseadas em nosso conhecimento, nossa vivência, nossa inteligência, para conter o avanço do coronavírus dentro do nosso território. Nosso bairro é popular. Nossa perspectiva de isolamento é sociointerativa, porque somos uma população culturalmente aglomerada. (Diogo, 2020).
\end{abstract}

Pensamos ser muito importante a compreensão mútua do sentido da Verdade contido na hermenêutica de Gadamer ${ }^{(2)}$ e no testemunho de Diogo. Dialogando com o autor da narrativa, à primeira vista, sua narração parece querer contrariar os pensamentos legítimos postos pela racionalidade científica de distanciamento físico, quando afirma duas contradições com a ideia de isolamento sociointerativo. No entanto, a interpretação hermenêutica da densidade dessa linguagem revela a lógica reflexiva da comunidade que se reconheceu confinada em si mesma, fosse pela fome, pelas ausências em saúde ou pelos encarceramentos sociais.

\begin{abstract}
Isolamento social, como as autoridades mandam, é ficar em casa. Mas, a gente sabe que não tem outra escolha, temos que sair e trabalhar, apesar de ser uma doença contagiosa. Tem um monte de gente fora da área de trabalho, mas também tem gente no ônibus e na feira, encarando... Bairro popular é feira, é fruta, é a banca de verduras que a gente frequenta. Aqui, o que mais a gente faz é ter contato. A gente pega e larga: a fruta, a feira, as pessoas. A gente tem contato direto: é um pega daqui e um pega dali. As autoridades esquecem que o beco da comunidade já é a residência de uma família. Às vezes, sete famílias moram no beco. Por isso, isolamento físico não dá certo, na comunidade... porque nossos corpos também são parte daquele espaço. Sempre tem algo que te puxa para perto do outro, seja a fruta, a comida, a casa ou o beco: sempre vai aglomerar gente. (Diogo, 2020)
\end{abstract}

Medidas severas de distanciamento físico e de mobilidade, tem-se mostrado efetivas para reduzir a epidemia em vários países. Estudos têm concluído que, o distanciamento social rigoroso, associado a uma intensa política pública de testagem, rastreamento de casos, contatos e quarentena, são capazes de manter a Covid-19 num nível que não ultrapasse a capacidade dos sistemas de saúde. ${ }^{(4)}$ No 
entanto, as ações de enfrentamento do Covid -19 pareceram estar dissociadas da vida na comunidade. O divórcio entre as intervenções pandêmicas e a realidade da comunidade pareceram carecer de soluções provenientes das políticas públicas que efetivamente tivessem transformado o estado de permanente pobreza daquele território.

A unidade narrativa guardou o significado hermenêutico-diacrônico(5) que revelou a inexistência de empenho histórico-político em solucionar as precarizações das vidas das famílias daquela coletividade, o que incluiu a SAN. Ao mesmo tempo, deu significado existencial aos fatores recorrentes que relativizaram a insalubridade com que a comunidade foi levada a enfrentar a pandemia e sua pontualidade emergencial.

Assim, a interpretação da imagem simbólica da narrativa foi à imposição da urgência de não poder ficar em casa, num momento em que as orientações sanitárias em Saúde Pública diziam o oposto, o que acabou por naturalizar o risco em plena pandemia, em prol de resolver a insegurança alimentar e nutricional.

Como a comunidade encontrou-se impossibilitada de exercer a liberdade de aderir aos significados complexos do bordão 'fique em casa', a mesma foi submetida pela lógica perversa imposta pela agenda mercadológica: escolher entre ficar em casa e morrer de fome ou sair de casa para trabalhar e arriscar-se à infecção pelo Covid -19 .

\begin{abstract}
$\mathrm{Na}$ comunidade a curva vai crescer, porque as estratégias de mandar ficar em casa, sem dialogar muito, só isolar a comunidade, mostra a dificuldade que os governantes tem com a gente. Da mesma forma que mandam isolar, higienizar as mãos e usar álcool gel, entendemos que o problema da comunidade não é o Covid -19 , mas é a falta de saúde. Nós não temos corpos saudáveis. Nossos corpos vivem se alimentando com aromatizantes. Quase ninguém mais diz que tem água na boca, quando sente um cheiro gostoso ou que comeu um alimento e sentiu um gosto agradável. Hoje em dia, a gente come porque tá salgadinho, tem muito açúcar, muita essência, aí, fica legal. Mas, nos tira a saúde. E isso mostra que essa é a comunidade no mundo de hoje: pessoas sem saúde, corpos deficientes. Os corpos da comunidade são corpos cansados, esquecidos pelos governantes, asfixiados, oxidados, intoxicados e inflamados por causa das porcarias com que nos alimentamos, do sedentarismo e do ar poluído que respiramos. (Diogo, 2020)
\end{abstract}

Nessa segregação urbano-residencial(6), de características multidimensionais, sobrepujaram assimetrias facilmente perceptíveis de direitos sociais, econômicos, 
jurídicos e ao direito humano à alimentação e nutrição adequadas (DHANA), mostrando a utopia das políticas públicas que pareceram conversar com as comunidades, sem conhecer suas realidades.

Como Gadamer evidenciou, a saúde é um estado oculto ${ }^{(7)}$ e a experiência da "falta de saúde", como disse Diogo, teve o sentido da ausência de uma escuta ativa da história das comunidades por parte do poder público. A fusão de horizontes entre a narrativa repleta de insalubridades e a impossibilidade de cumprir distanciamento físico por parte da população economicamente vulnerável pareceu estar sustentada por uma hipocrisia do discurso governamental.

A experiência de Diogo aproximou significados hermenêuticos que propuseram múltiplos contextos em SAN na comunidade. Dentre esses, importou o significado de que nem a população vulnerável, nem os anseios médico-sanitários pareceram estar conscientes de que as relações de poder que vem mantendo historicamente as estruturas da fome cônica na comunidade são as mesmas que compelem à desobediência ao distanciamento social.

$\mathrm{Na}$ Bahia, desde o início da confirmação de casos de coronavírus, um conjunto de ações para o enfrentamento da pandemia foi articulado por Decretos Governamentais( $^{(8)}$ visando a prevenção, monitoramento e contenção de agravos à saúde pública pela Covid-19. Medidas como restrição de circulação de pessoas, antecipação de feriados, toques de recolher, suspensão de transportes, eventos, aulas, dentre outras, deram o tom das tentativas de reduzir a transmissão da doença. A mitigação(9), fase que acontece acompanhada de ações que aumentem o distanciamento social, visou retardar o contágio da infecção e restringir a onda epidêmica.

As tomadas de medidas sociais de saúde pública de larga escala, foram extensivas a toda população baiana e, o extrato social, que se encontrava em maior vulnerabilidade, foi incluso em algumas formas de auxílios emergenciais. Citamos aqui os subsídios estaduais que disseram respeito especificamente a SAN como, por exemplo, destinação de recursos para pagamento das faturas residenciais de água(10), criação do Projeto Vale Alimentação Estudantil (PVAE), que transferiu renda aos estudantes da rede pública estadual de ensino como benefício complementar emergencial para manutenção da alimentação escolar no período de 
suspensão das atividades letivas ${ }^{(11)}$ e o auxílio emergencial protagonizado pelo Congresso Nacional, destinado aos trabalhadores informais, microempreendedores individuais, autônomos e desempregados, para proteção durante três meses, no valor de $\mathrm{R} \$ 600,00$ ou $\mathrm{R} \$ 1.200,00$ (no caso de mulheres única responsável pelas despesas da casa). ${ }^{(12)}$

\begin{abstract}
A gente sabe que essa situação de não ter condições de comprar muitos alimentos é uma coisa real na nossa comunidade. A nossa comunidade não tem condições de comprar todos os dias, por exemplo, cinco ou quatro Reais de pão, principalmente quem tem família grande. Esses seiscentos contos do auxílio emergencial não dão conta de comprar comida e pagar o aluguel. E, ainda tem todas as filas para tentar receber o auxílio emergencial, fora as necessidades que a comunidade tem de trabalhar, buscar frutas e legumes no atacado para vender nas feiras livres e se sustentar. O que tento dizer é que nós continuamos na pista, trabalhando e vendo como sobreviver ao coronavírus e a curva está subindo... pior é saber que eles dizem que a culpa é nossa. (Diogo, 2020)
\end{abstract}

O sentido moral de culpa atribuído por outros neste momento pandêmico, como se as ações da população da comunidade fossem uma escolha desse papel social, expressou a face fenomenológica perversa dos significados assistencialistas complexos entre os agenciamentos políticos, mercadológicos e sociais, que se contrapuseram às esferas do DHANA. O contexto da narrativa apresenta alguns significados interpretativos e sugerem a carga de um sofrimento que não está sob o poder da comunidade resolver. A pandemia está acelerando o processo da fome no país e, segundo Balaban (2020), entre os anos "2015 a 2019 a extrema pobreza aumentou 73\%".(13)

É primordial levar em conta a interpretação do dilema ético da comunidade, quanto a necessidade de, por um lado, seguir as prerrogativas preconizadas pela OMS e decretadas pelos governantes e, por outro, precisar diluir o impacto sanitário da Covid-19 frente às tensões da fome e dos significados da urgência de um presente que se impôs, mas que não foi preparado no passado. Ficar em casa, para a comunidade, comprometeria a obtenção do alimento, quando o comer seria o eixo que gira a roda. A interpretação da narrativa revelou que a SAN é o liame de uma cadeia interminável, que estrutura as relações da saúde, economia, proteção social e, também, a possibilidade de cumprir ou não o distanciamento social. 
A Organização Mundial de Saúde (OMS) disponibilizou instrumentos para realização de avaliações de risco para aglomerações e implantação de estratégias que possibilitam o retardo da propagação exponencial do coronavírus. ${ }^{(14),(15)} \mathrm{O}$ objetivo primordial dessas determinações foi reduzir a taxa de transmissão e mortalidade associadas ao Covid-19, implementando medidas de controle que abrangessem desde a identificação de casos, testagem, isolamento dos casos identificados, cuidados médicos para todos os casos, rastreamento e quarentena para todos os contatos, além de medidas de saúde pública individual e comunitária, que não são mutuamente excludentes e compreendem uso de máscaras, álcool gel 70 graus e distanciamento físico.

Outras medidas sociais de saúde pública de larga escala foram implementadas e, incluíram restrições de movimentação e contato social, através do fechamento do comércio e escolas. A orientação da OMS é que, até que existam medidas farmacológicas como terapias medicamentosas ou vacina, países baseiemse em evidências cientificas e experiências reais, levando em consideração fatores econômicos, direitos humanos e segurança alimentar para intensificar, afrouxar ou reinstalar as medidas sociais de saúde pública de larga escala. (16)

A estratégia do governo baiano foi alcançar crianças e adolescentes das camadas populares através da criação de um subsídio de $R \$ 55,00$ mensais para cada estudante matriculado nas escolas públicas estaduais para aquisição apenas de alimentos. Para isso, lançou mão de recursos próprios daquele Estado(11), respondendo a um alcance de certa medida de SAN para famílias de baixa renda durante a pandemia.

Num olhar interpretativo que dialogou hermeneuticamente com alguma solução para a crise sanitária que se instalou, as ações que incluíram subsídios para alimentação dos estudantes das camadas populares podem ter sido capazes de alcançar certo grau de abastecimento alimentício nos lares vulneráveis. Assim, focalizando um momento pós pandêmico, talvez a implementação dos benefícios de alimentação escolar nominal a cada estudante possa ser ampliada e desburocratizada, de modo a vincular famílias que vivem em estado crônico de pobreza. Essa discussão sobre a renda mínima infantil(17) ampliaria a rede de 
proteção social evidenciando crianças e adolescentes de baixa renda, numa tentativa de redução da insegurança alimentar e nutricional.

\section{A Poesia que a Comunidade Escuta}

A crise sanitária pelo Covid-19 que se instalou de forma vertiginosa no Brasil, têm atingido a comunidade como um bombardeio multidirecional por causa da fome aguda, que se vinculou à necessidade de continuar desobedecendo ao regramento sanitário de distanciamento social. Dessa forma, o coronavírus provocou a exposição da conjuntura da comunidade que, em sua nudez, mostrou múltiplos significados da fome crônica, ao denunciar a desconstrução da cidadania de cada um de seus habitantes. A interpretação da naturalização política da insegurança alimentar e nutricional foi caracterizada agora, pelo medo de estar na comunidadecasa e também de estar fora dela. O medo pareceu ser então, o único lugar de viver para essa comunidade, o que compôs uma hermenêutica desse significado como verdade ontológica, durante a pandemia por Covid-19.

\footnotetext{
A gente entende que o coronavírus vai pegar todo mundo, porque os corpos de todo mundo aqui estão doentes. Então, é preciso que a gente rapidamente recomponha a saúde, se alimentando todos os dias com alimentos plantados. Aqui, a gente crê que para enfrentar a pandemia é preciso comer alimentos naturais, alimentos plantados. Semelhante ao lavar as mãos e usar álcool gel, o alimento plantado vai higienizar seu corpo por dentro. Comer as substâncias naturais vai ajudar a dinamizar o corpo. (Diogo, 2020)
}

A identidade coletiva remanescente quilombola pareceu querer gritar nas narrativas de Diogo. Frente ao Covid-19, o sentido ancestral da alimentação afrodescendente recriou o caminho do plantador, como resistência. O simbolismo transcendental pode ser interpretado como uma alegoria capaz de vencer o monstro Coronavírus. Na estrutura da narrativa, os corpos dos moradores da comunidade encontraram-se entremeados em almas, espíritos e desejos por plantios, colheitas, comidas e sabores que tentavam desinfetar as injustiças sociais crônicas, o coronavírus e, ainda, germinar saúde.

Para enfrentar a pandemia, os moradores da comunidade "vivem através de um direito sonâmbulo" (Andrade, 1928), só encontrando o não-lugar como 
possibilidade de isolamento físico. Assim, suas experiências comunicaram na unidade de sentido(2) da linguagem, interpretações que desnudaram os segredos da sobrevivência, ao sobejar os atos de comer alimentos que contam a história da sobrevivência de suas gerações. Comer as plantações teria o sentido de voltar a comer as memórias formativas, como que estivessem refazendo o Manifesto Antropófago de Oswald de Andrade. ${ }^{(18)}$

Diogo expôs experiências narrativas antepassadas que falavam de um ser comunitário. Essa interpretação relacionou a vivência à coletividade, narrando a si próprio, mas também se conectando a todos os que se encontraram assemelhados as suas realizações alimentares. Pareceu que a brutalidade de ter que driblar em plena pandemia, os impedimentos que não os desejam vivos, estão descritos no intrínseco lugar dos silêncios da narrativa.

A fragilidade das forças humanas desses moradores quilombolas pareceu encontrar sentido na realização da compreensão(2) da SAN enquanto uma imagem metafórica do alimento provocando uma assepsia biomolecular, gerada pelo ideal simbólico da alimentação sustentável vencendo o Covid-19.

$\mathrm{Na}$ narrativa apresentada, interpretou-se o jogo mercadológico do biopoder imposto pelas necessidades do comer, da fome e do "fique em casa". A estrutura de pergunta e resposta ${ }^{2}$ implícita nas entrelinhas da narrativa (tenho que ficar em casa, não posso ficar em casa, o que devo fazer?) deram significado a um enigma de interpretação hermenêutica.

A comida passou a ser vista como o espaço central na configuração da narrativa, podendo ser explicada como a própria casa, já que é dela que não se pode distanciar e é nela que é preciso ficar, para poder sobreviver à História e, também, ao novo coronavírus. Assim, o alimento tem significado de lugar de pouso, o próprio Ki lombo ${ }^{8}$, lugar de proteção.

A realidade do Covid-19 está na representação do significado da comida, mesmo que o prato esteja vazio. A redistribuição dos comportamentos e costumes observados durante a pandemia, girou em torno dos mercados essenciais, como o

\footnotetext{
${ }^{8} \mathrm{Ki}$ lombo: léxico quilombo em sua expressão africana originária da língua angolana kibundu (Ki lombo) ou umbundo (ochilombo), falada pelos povos bantos. Greeb D, Labigalini V, Barban V. Ancestralidade africana no Brasil: memória dos pontos de leitura. São Paulo: Instituto de Políticas Relacionais, 2014
} 
da alimentação e provou que a comunidade não é assenhorada de si ao ponto de decidir parar ou poder publicar o que se come. A fome nas comunidades mais vulneráveis mostrou ao país que a comunidade não parou de se movimentar e seu trabalho intenso e ininterrupto manteve não só a subsistência, mas também o fluxo das agendas mercadológicas. "Aqui, temos duas imagens para ver: uma, quando eles postam o prato cheio e outra, quando nós, postamos o prato vazio" (Diogo, 2020).

A funcionalidade fronteiriça do significado compreensivo dos léxicos 'eles' e 'nós' transbordaram interpretações hermenêuticas que incluíram os moradores da comunidade também no grupo de trabalhadores de enfrentamento do novo coronavírus. Sem treinamentos ou equipamentos de proteção individual (EPI), estiveram nas madrugadas das feiras livres e vararam dias realizando serviços que não podiam parar. Essa comunidade encontrou-se sob maiores riscos, porque também não tinham o lugar de distanciamento físico para onde voltar.

Sua esperança ainda foi a comida que plantaram ter algum tipo de efeito mágico que potencializasse a saúde. Por outro lado, sua desesperança foi a mesma comida ser seu principal problema econômico durante o confinamento. Movendo-nos entre os termos da narrativa ${ }^{19}$, percebemos que o fluxo entre sua interpretação e seu significado simbólico foi o prato vazio. A comunidade não pode parar de trabalhar para se distanciar socialmente. Isso equivaleria à demarcação da reminiscência escrava com a fome, podendo ser traduzida como o lugar histórico da Verdade 2.

O distanciamento físico pareceu residir num futuro longínquo e o enfrentamento da fome em tempos de Covid-19 tornou-se como um impacto diluído nas alterações das vidas que continuaram em movimento por lá. Os becos, as ruas estreitas, os barulhos, o chão sem asfalto, as deficiências de água e energia elétrica, a mão de obra barata e a fome: todos esses agentes estão funcionando como laços na experiência hermenêutica ${ }^{2}$. Os sentidos da poética da coesão social foram caminhando na contramão dos isolamentos e dos lockdown, e acabaram declamando congraçamentos que sempre se referiram ao comer: "O feriadão na comunidade é mentiroso. Na comunidade feriadão é aglomeração, é churrasco" (Diogo, 2020) 
O contexto da mensagem trouxe o significado de que o confinamento em si mesma e a impossibilidade de realização do distanciamento físico não conseguiriam submeter a comunidade, enquanto coletividade, à ameaça do novo coronavírus. Isso se deveu aos fatores multicausais, incluindo a consciência de pertencimento e unidade entre os membros da comunidade. ${ }^{2}$

Só um amigo pode aconselhar o outro ou, dito de outra maneira, somente um conselho com intenção de amizade pode ter sentido para 0 aconselhado. Também aqui se torna claro que o homem compreensivo não sabe nem julga a partir de um simples estar postado frente ao outro de modo que não é afetado, mas a partir de uma pertença específica que o une com o outro, de modo que é afetado com ele e pensa com ele. (Gadamer [328], p.425)

Interessante o sentido de que a vida na comunidade foi estabelecida em torno do pertencimento comunitário. Interpretou-se, assim, que os elementos característicos da amizade e do vínculo de confiança entre seus moradores apareceram antropomorfizados no carro do ovo ${ }^{9}$. Por analogia, as semelhanças nas características históricas de origem e de enfrentamento de problemáticas que aproximaram os elos da comunidade, tornaram as experiências com o carro do ovo estratégicas para anunciar proteção individual contra a Covid-19 e, ao mesmo temo, ser o lugar da comida. A interpretação da narrativa do carro do ovo mostrou a importância do emissor do discurso do isolamento físico.

\footnotetext{
O carro do ovo faz parte da estratégia de contenção do coronavírus. A comunidade escuta o carro do ovo porque não é uma fala qualquer: é uma poesia aqui da comunidade $O$ carro do ovo vem com sua estratégia de divulgar a ideia que ele acredita. Por exemplo, o carro do ovo já disse assim: o Covid veio da China. Use máscara e venha pegar o ovo! A comunidade ouve isso. (Diogo, 2020)
}

A interpretação da escuta ativa do carro do ovo pela comunidade pareceu questionar: como querem promover distanciamento social contra o Covid-19 na comunidade, sem interagir com ela? A fragilidade da euforia do pensamento mágico, de que todos na cidade ficariam distanciados fisicamente ao mesmo tempo,

\footnotetext{
${ }^{9}$ Carro do ovo: trata-se de um empreendedorismo com dimensões econômicas e culturais, que vende grande quantidade de ovos a preços baixos em bairros populares e anunciam outras mensagens, através de um carro, geralmente Kombi, munido de alto-falante.
} 
encontrou interpretação análoga na comunidade de que nem todos os dias a comida iria estar presente e esse conflito amparou o risco a que se submeteu a comunidade, ao sair de casa.

\section{Considerações Finais}

Parece que dentro da perspectiva hermenêutica, a relação do poder público com a comunidade precisa ser de escuta ativa. A comunidade compreendeu que o pensar e o fazer saúde em tempos de restrições sanitárias causadas pelo novo coronavírus se estabeleceram de forma impositiva e sem as explicações, o que somente os de casa poderiam fazer. Para a comunidade, dizer 'não' ao distanciamento físico, não significou o que se viu na superfície, uma simples desobediência ou resistência. Mas adentrou o mundo das possibilidades e impossibilidades, as quais tiveram significados interpretativos múltiplos, sempre com a SAN sendo o tema central.

A dificuldade em cumprir o distanciamento assemelhou-se ao não querer morrer de fome frente a exclusão do mundo do trabalho, fosse ele formal ou informal. Ao mesmo tempo, simbolizou sentidos encharcados de silêncios traduzíveis pelo sonho do atendimento diferencial para a comunidade.

Compreendeu-se, das interpretações hermenêuticas, que é preciso que o poder público comece a planejar agora o momento pós-pandemia para construir uma agenda ativa de proteção a SAN nas comunidades. Entendeu-se que, através de uma renda mínima infantil relacionada à alimentação escolar, boa parte das populações economicamente vulneráveis seriam alcançadas.

O horizonte histórico da fome na comunidade estudada fundiu-se com os medos das ausências. A comida: aglomeração, o novo coronavírus: doença, a máscara: proteção, a casa: beco, o carro do ovo: conselheiro, são imagens acústicas de uma densa tempestade interior da interpretação de sentidos do distanciamento físico, que nenhum deles ali conseguiria resolver. O tempo-social falou do significado simbólico de vencer um contexto de carências numa cadência que se justificou na comida saudável, sustentável, "plantada". 
A narrativa dessa classe social apontou perspectivas hermenêuticas que nos ajudaram a compreender os pertencimentos que os fizeram ter a liberdade de pegarlargar, fosse a fruta, a comida, a feira ou as lacunas que os sistemas múltiplos de responsabilidade econômica e social impuseram sobre a comunidade. O custo socio-histórico de se "continuar na pista" e lutar pela comida na mesa, guerreando com as possibilidades de infecção por Covid-19 foi a própria vida.

A estratégia da comunidade para lidar com o comer durante a crise sanitária pareceu ser atingida em cheio por um desequilíbrio socioeconômico versus saúde. Foi de grande perversidade que as populações vulneráveis precisassem escolher entre sair para trabalhar e assim, conseguir seu alimento, arriscando-se a contrair a infecção por Covid-19, ou permanecer aglomeradas no beco, sem trabalhar, por medo da infecção e morrer mesmo assim, fosse pela fome ou pelo coronavírus.

Sua história de coesão social mostrou o quanto a comunidade se antecipou como agente de transformação e proteção do seu território, através de saberes empíricos que estiveram adjuntos aos acordos sociais da comunidade. Essa compreensão que a população teve está guardada no olhar que integrou sua identidade à natureza. A consciência deste ser identitário, mostrou-se presente nas memórias de pertencimento, que a comida de origem pode fazer brotar. Muitas e muitos Diogos, estão agora comendo uma "comida plantada", para conseguir interpretar o distanciamento social que se impôs para além das fronteiras da comunidade.

\section{Referências}

(1) Bauer MW, Gaskell G. Pesquisa qualitativa com texto, imagem e som. 3.ed. Petrópolis, RJ: Vozes; 2015.

(2) Gadamer HG. Verdade e método: traços fundamentais de uma hermenêutica filosófica. 15.ed. Petrópolis,RJ: Vozes, 2016.

(3) Wolfe N. The viral storm: the dawn of a new pandemic age. New York: Times Book; 2011.

(4) Aleta A, Martin-Corral D, Pastore y Piontti A, Ajelli M, Litvinova M, Chinazzi M, et al. Modeling the impact of social distancing, testing, contact tracing and household quarantine on second-wave scenarios of the COVID-19 epidemic. MedRxiv; May, 2020. [Acesso em 10 jun 2020]. Disponível em: doi:

https://doi.org/10.1101/2020.05.06.20092841. 
(5) Steiner G. Depois de Babel: questões de linguagem e tradução. Curitiba: Editora UFPR; 2005.

(6) Moro E. Ciudades em alta resolución: usando Big Data para entender la segregación social. Conferência Demography Today. Fundacion Madrid: BBVA; 2018. [Acesso em 08 jun 2020]. Disponível em:

https://www.fbbva.es/eventos/ciudades-en-alta-resolucion_usando-big-data-paraentender-la-segregacion-social/

(7) Gadamer, H G El Estado Oculto de la Salud. Barcelona: Gedisa; 1996.

(8) Bahia. Governo do Estado. Secretaria de Comunicação Social. Entenda as medidas de combate ao coronavírus na Bahia. Bahia: SECOM - Imprensa Oficial; 06 de junho de 2020. [Acesso em 10 jun 2020 ]. Disponível em:

http://www.secom.ba.gov.br/2020/03/152898/Entenda-as-medidas-de-combate-aocoronavirus-na-Bahia.html

(9) Kissler S, Tedijanto C, Lipsitch M, and Grad HY. Social distancing strategies for curbing the COVID-19 epidemic. Harvard University's DASH Repositor; March 2020. [Acesso em 10 jun 2020]. Disponível em: http://nrs.harvard.edu/urn3:HUL.InstRepos:42638988.

(10) BAHIA. Lei No 14.256 de 06 de abril de 2020. Autoriza o Poder Executivo a destinar recursos para pagamentos das faturas residenciais de água de consumidores de baixa renda beneficiários de tarifa social que residam no Estado da Bahia, na forma que indica. Diário Oficial do Estado da Bahia 07 abril 2020. [Acesso em 08 jun 2020] Disponível em:

http://www.secom.ba.gov.br/arquivos/File/COVID_Decretos/Lei142562020.pdf

(11) Bahia. Lei № 14.259 de 14 de abril de 2020. Cria o Projeto Vale Alimentação Estudantil - PVAE, destinado a ações de transferência de renda aos estudantes da rede pública estadual de ensino, configurando benefício complementar emergencial, em razão do estado de calamidade pública em saúde decorrente da pandemia da COVID-19, e dá outras providências. Diário Oficial do Estado da Bahia 15 abril 2020. [Acesso em 08 jun 2020]. Disponível em:

http://www.secom.ba.gov.br/arquivos/File/lei14259.pdf

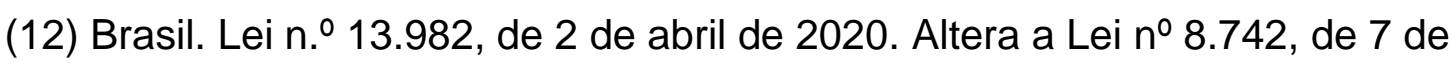
dezembro de 1993, para dispor sobre parâmetros adicionais de caracterização da situação de vulnerabilidade social para fins de elegibilidade ao benefício de prestação continuada (BPC), e estabelece medidas excepcionais de proteção social a serem adotadas durante o período de enfrentamento da emergência de saúde pública de importância internacional decorrente do coronavírus (Covid-19) responsável pelo surto de 2019, a que se refere a Lei no 13.979, de 6 de fevereiro de 2020. Diário Oficial da União 02 abril 2020; Ed.64-A, Seção 1-Extra. P.1. [Acesso em 08 jun 2020]. Disponível em: http://www.planalto.gov.br/ccivil_03/_ato20192022/2020/lei/l13982.htm

(13) Balaban D. Só um grande pacto nacional livrará o Brasil de consequências sociais terríveis. Gauchazh. 2020 maio 22. [Acesso em 29 mai 2020]. Disponível em: https://gauchazh.clicrbs.com.br/mundo/noticia/2020/05/so-um-grande-pacto- 
nacional-livrara-brasil-de-consequencias-sociais-terriveis-alerta-economista-da-onuckai93m3n0057015ncdcwqgy1.html

(14) Organização Mundial de Saúde. How to use WHO risk assessment and mitigation checklist for Mass Gatherings in the context of COVID-19: interim guidance. Geneva: WHO; 19 March 2020. [Acesso em 10 jun 2020]. Disponível em: https://www.who.int/publications/i/item/how-to-use-who-risk-assessment-andmitigation-checklist-for-mass-gatherings-in-the-context-of-Covid-19.

(15) Organização Mundial de Saúde. Decision tree for risk assessment for mass gathering. Geneva: WHO; 8 April 2020. [Acesso em 07 jun 2020]. Disponível em:https://www.who.int/docs/default-source/coronaviruse/who-2019-ncov-mgdecision-tree.pdf?sfvrsn=35435b5a_2\&download=true

(16) Organização Mundial de Saúde. Considerations in adjusting public health and social measures in the context of COVID-19: interim guidance. Geneva: WHO; 16 April 2020. [Acesso em 06 jun 2020]. Disponível em:

https://apps.who.int/iris/handle/10665/331773

(17) Debolle M. O que não custa? O Estado de São Paulo. 2020 junho 10. [Acesso em 10 jun 2020]. Disponível em: https://economia.estadao.com.br/noticias/geral,oque-nao-custa,70003330014

(18) Andrade O. Manifesto Antropófago. Revista de Antropologia, anno I, n. I, p. 3 e 7, maio 1928. [Acesso em 25 mai 2020]. Disponível em: https://pib.socioambiental.org/files/manifesto_antropofago.pdf

(19) Minayo MCS de. Hermenêutica: Dialética como caminho do pensamento social. In: Minayo MCS, Deslandes SF (org). Caminhos do pensamento: epistemologia e método. Rio de Janeiro: Editora FIOCRUZ; 2003. 